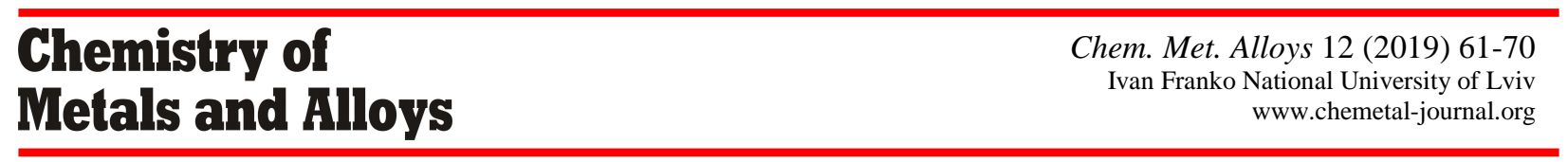

\title{
Calculation of cation migration channels in crystals with scheelite- type structures
}

\author{
V.N. SHEVCHUK ${ }^{1 *}$ I.V. KAYUN ${ }^{1}$ \\ ${ }^{1}$ Department of Electronics and Computer Technologies, Ivan Franko National University of Lviv, \\ Drahomanova St. 50, 79005 Lviv, Ukraine \\ * Corresponding author. Tel.: +380-32-394326; e-mail: shevchuk@electronics.lnu.edu.ua
}

Received October 25, 2019; accepted December 18, 2019; available on-line April 1, 2020

https://doi.org/10.30970/cma12.0389

\begin{abstract}
A stereo-atomic crystal structure analysis was applied to $A \mathrm{WO}_{4}(A=\mathrm{Ca}, \mathrm{Pb})$ crystals. The program package TOPOS was used for the calculations. $3 D$ migration paths for the $W$ ions in the $A W O_{4}$ compounds at different temperatures were visualized. Peculiarities of the migration paths and the conditions for possible ionic conductivity in crystals with scheelite-type structures were considered. The influence of the introduction of $\mathrm{Eu}^{3+}$ ions on the migration path of the $\mathrm{W}$ ions in $\mathrm{CaWO}_{4}$ was analyzed. The temperature dependencies of the lengths of particular elementary channels and their evolution with variations of the unit-cell parameters of the crystals were considered in connection with the conditions of the synthesis of the compounds.
\end{abstract}

$A \mathrm{WO}_{4}(A=\mathrm{Ca}, \mathrm{Pb}) / \mathrm{CaWO}_{4}: \mathrm{Eu}^{3+} / \mathrm{TOPOS} /$ Cation migration / Migration map / Scheelite

\section{Introduction}

Crystals with scheelite-type structures are important as widely known modern materials and as work elements in detector systems. In all cases the scientific and technical applications of the crystals strongly depend on point defects (or disorder) in the crystal structure. Electrical conductivity investigation is a basic method to study crystal structure disorder. But the electrical conductivity, and specifically the ionic conductivities of $A \mathrm{WO}_{4}$ (where $A$ is $\mathrm{Ca}$ or $\mathrm{Pb}$ ) crystals and other compounds with scheelite-type structures, are not well known. The type and migration way of the ionic charge carriers in these crystals have up to now not been sufficiently studied, i.e. the mechanism of ionic conductivity and the migration paths of the mobile ions in the $A \mathrm{WO}_{4}$ crystals have not been ascertained.

The electrical properties of $A \mathrm{WO}_{4}$ crystals were in our previous papers [1-3] investigated in connection with the crystal structure. In the calculation works [4-6] we presented the first visualization data of the 3D-migration path of Mo or $\mathrm{W}$ ions by using the TOPOS program complex. The visualization of possible migration paths of ionic charge carriers is an important method for the determination of the micromechanism of their movements through the crystal structure. But the regularities and details of the calculation of the probable migration paths of the $\mathrm{W}$ ions in $\mathrm{AWO}_{4}$ crystals had not yet been completely investigated.
For the analysis of the ion migration and for the visualization of the ion pathways in different oxides, $a b$ initio techniques can be utilized (see e.g. brief reviews in [5], [7], and [8]). In the works by Filsoe et al. $[7,8]$ the procrystal analysis is presented as a valuable tool for the visualization of ion migration in solids. The present study, using the program package TOPOS [9] with the aim to analyze the microstructure of the possible migration paths of the $\mathrm{W}$ ions in $A \mathrm{WO}_{4}$, is devoted to the calculation and construction of the $\mathrm{W}$-migration path in the above-mentioned compounds. The electrotransfer process simulation, performed with the aid of the TOPOS program, is the first step for the estimation of possible cation migration in the structure. The next stages of the problem are specific experimental investigations of the high-temperature electrical conductivity and testing for the presence of ion migration.

In this paper we give a summary of published experimental structural data on $A \mathrm{WO}_{4}$ and own results from X-ray diffraction. We consider the possible $\mathrm{W}$-migration ways and the temperature dependence of characteristic elementary parameters of the cation transfer, in particular the lengths of elementary channels. The calculated migration channels are then compared with the variation of the unit-cell parameters of the $\mathrm{AWO}_{4}$ compounds. The consideration of structural factors and the visualization of conduction pathways lead to the determination of mechanisms of ion migration and allow the prediction of crystal properties and applications. 


\section{Experimental and calculation procedures}

The $\mathrm{CaWO}_{4}$ and $\mathrm{PbWO}_{4}$ crystals (scheelite-type structure, space group $\left.\mathrm{C}_{4 \mathrm{~h}}^{6}-I 4_{1} / a\right)$ used for the study were obtained by the Czochralski technique [3]. Crystals of the same compounds with scheelite-type structures have been obtained by different authors and methods (see Tables 1 and 2). The theoretical density of the crystals (Tables 1 and 2) was computed from X-ray diffraction (XRD) data. The XRD analysis was performed on a STOE STADI $P$ powder diffractometer equipped with a linear positionsensitive detector PSD. Arrays of experimental intensities and diffraction angles were obtained in a modified Guinier geometry scheme in Bragg-Brentano transmission mode. Conditions of the measurements: monochromatic $\mathrm{Cu} \mathrm{K \alpha} \alpha_{1}$ radiation $(\lambda=1.540598 \AA$ ) ; bent Johann-type [111] Ge-monochromator; $\omega / 2 \theta$-scan; $2 \theta$-range $4^{\circ} \leq 2 \theta \leq 120^{\circ}$; step $0.480^{\circ}(2 \theta)$; step scan time $250 \mathrm{~s}$. Other details of the XRD-measurements have been described previously $[2,29]$. The search for other structural data of the
$A \mathrm{WO}_{4}$ compounds was performed using Pearson's Crystal Data [30].

In this work, using the TOPOS program package [9,31], we constructed possible $\mathrm{W}$-ion migration maps for the $A \mathrm{WO}_{4}$ crystals. The possible migration paths of the $\mathrm{W}$ ions in the crystal structure at different temperatures (X-ray data for $\mathrm{PbWO}_{4}$ and $\mathrm{CaWO}_{4}$ from to [19] and [23], respectively) and the variation of the unit-cell volume (data in Tables 1 and 2) were analyzed.

Voronoi tessellation was used for the analysis of possible ionic migration [32,33]. Within this approach the atomic Voronoi polyhedrons were constructed. The map of elementary voids and channels is consistent with experimental data. The basic concepts for the description of voids and channels are the following: elementary void (channel), and the closely related terms of form and radius of void, significant elementary void (channel). The Voronoi polyhedron (VP) of an atom (geometric image atom) is defined $[9,31]$ by the value of the second moment of inertia $(G)$.

Table 1 Methods of crystal growth and crystallographic data of $\mathrm{PbWO}_{4}$ used for the calculations.

\begin{tabular}{|c|c|c|c|c|c|}
\hline \multirow{2}{*}{ Ref. } & \multirow{2}{*}{ Crystal growth } & \multicolumn{2}{|c|}{ Unit-cell parameters $(\AA)$} & \multirow{2}{*}{$\begin{array}{c}\text { Unit-cell volume } \\
\qquad\left(\AA^{3}\right)\end{array}$} & \multirow{2}{*}{$\begin{array}{l}\text { Density } \\
\left(\mathrm{g} / \mathrm{cm}^{3}\right)\end{array}$} \\
\hline & & $a$ & $c$ & & \\
\hline this work & Czochralski & 5.4601 & 12.0425 & 359.02 & 8.4216 \\
\hline [10] & Czochralski & 5.4560 & 12.0200 & 357.81 & 8.4421 \\
\hline [11] & Czochralski & 5.4360 & 11.9570 & 353.33 & 8.5542 \\
\hline [12] & mechanical alloying & 5.4661 & 12.0779 & 360.87 & 8.3756 \\
\hline [13] & $\begin{array}{c}\text { conventional } \\
\text { solid-state reaction }\end{array}$ & 5.4597 & 12.0420 & 358.95 & 8.4203 \\
\hline [14] & Czochralski ? & 5.4646 & 12.0479 & 359.77 & 8.1715 \\
\hline [15] & natural & 5.4450 & 12.0495 & 357.24 & 8.4605 \\
\hline [16] & $\begin{array}{c}\text { complex } \\
\text { polymerization }\end{array}$ & 5.4637 & 12.0654 & 360.18 & 8.3916 \\
\hline [17] & precipitation & 5.4645 & 12.0553 & 359.98 & 8.3962 \\
\hline [18] & polycrystal & 5.3851 & 11.7223 & 339.94 & 8.8912 \\
\hline [19] & Czochralski & 5.4632 & 12.0482 & 359.60 & 8.4051 \\
\hline
\end{tabular}

Table 2 Methods of crystal growth and crystallographic data of $\mathrm{CaWO}_{4}$ used for the calculations.

\begin{tabular}{c|c|c|c|c|c}
\hline \multirow{2}{*}{ Ref. } & \multirow{2}{*}{ Crystal growth } & \multicolumn{2}{|c|}{ Unit-cell parameters $(\AA)$} & Unit-cell volume & \multirow{2}{*}{$\begin{array}{c}\text { Density } \\
\left(\mathrm{g} / \mathrm{cm}^{3}\right)\end{array}$} \\
\cline { 3 - 4 } & & $\boldsymbol{a}$ & $\boldsymbol{c}$ & 312.02 & 6.1294 \\
this work & Czochralski & 5.2394 & 11.3663 & 312.95 & 6.1112 \\
{$[20]$} & nanopowder & 5.2433 & 11.3831 & 313.08 & 6.1087 \\
{$[21]$} & co-precipitation & 5.2448 & 11.3818 & 312.64 & 6.1172 \\
{$[22]$} & Lab. Bell & 5.2429 & 11.3737 & 312.86 & 6.1130 \\
{$[23]$} & Czochralski & 5.2442 & 11.3759 & 312.62 & 6.1175 \\
{$[24]$} & polycrystal & 5.2425 & 11.3748 & 313.61 & 6.0983 \\
{$[25]$} & nanopowder & 5.2485 & 11.3846 & 311.33 & 6.1429 \\
{$[26]$} & Czochralski & 5.2360 & 11.2360 & 312.72 & 6.1157 \\
{$[27]$} & Lab. Bell & 5.2430 & 11.3760 & 313.40 & 6.1024 \\
\hline 28$]$ & nanopowder & 5.2470 & 11.3834 & & \\
\hline
\end{tabular}


The elementary void is an area of the crystallographic unit cell, the center of which is one of the vertexes of a Voronoi polyhedron. Major (ZA) and minority (ZC) elementary voids with sequence numbers $N$ (ZAN and $\mathrm{ZCN}$ ) are considered. An atom can pass through an elementary channel if the sum of its radius $\left(r_{\mathrm{i}}\right)$ and the average radius of the atoms forming the channel $\left(r_{a}\right)$, is less than the radius of the channel cross section $\left(r_{\mathrm{c}}\right)$. In order to take into account possible polarization (deformation) of the ions when they pass through the channel, the coefficient of deformation $\gamma_{\mathrm{i} a} \leq 1$ was introduced. An ion passes through the channel if $\gamma_{\mathrm{i} a}\left(r_{\mathrm{i}}+r_{a}\right) \leq r_{\mathrm{c}}$.

Within the framework of the program package TOPOS the migration pathway is determined as a set of elementary voids and lines of elementary channels. It can be infinite along a 1D-, 2D-, or 3D-channel network. The conduction map is formed by the totality of migration pathways. For fast-ion conductors endless migration paths are required. In other real crystals even in the case of a continuous channel network, high ionic conductivity is not always observed experimentally.

The algorithm based on the analysis of the adjacency matrix of the crystal structure (see for example our previous paper [32]) includes four steps: (i) construction of the VP for all atoms; (ii) determination of the atomic coordinates of the vertices of the VP and the positions of elementary voids; (iii) identification of all independent edges of the VP and all basic channels; (iv) calculation of the basic characteristics of the voids and channels. The availability of structural data for the $A \mathrm{WO}_{4}$

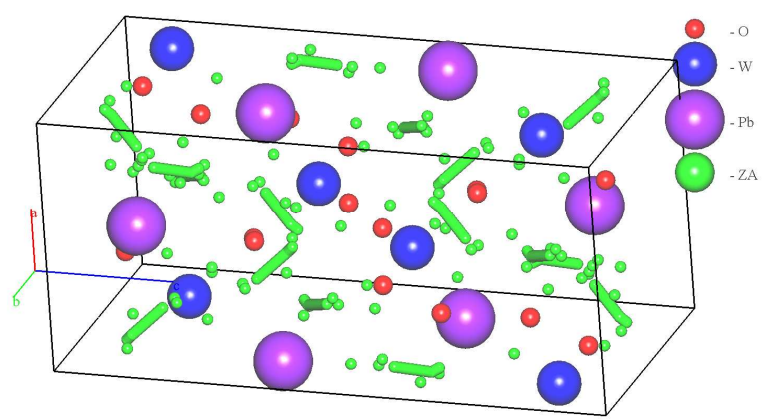

a

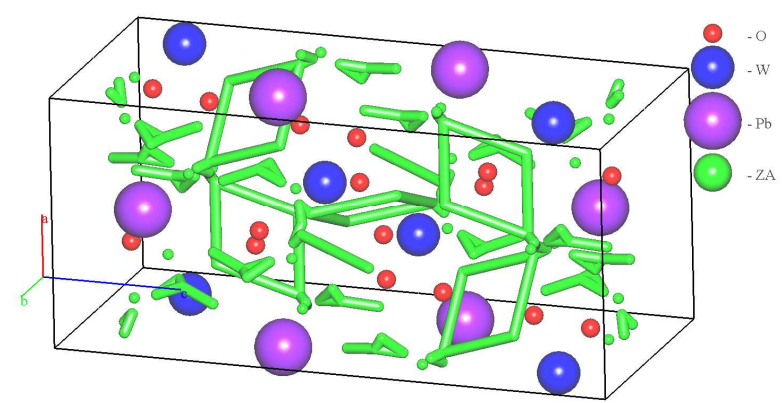

c compounds at room and other [19,23] temperatures motivated the choice of this class of compounds as a model object for mapping of the ion migration and calculation of the structural elements of the coordination polyhedra. For the calculation we used the following ionic radii: $\mathrm{W}^{6+}(0.56 \AA)$ for coordination number $4, \mathrm{Ca}^{2+}(1.26 \AA), \mathrm{Pb}^{2+}(1.43 \AA)$ for coordination number 8 , and $\mathrm{O}^{2-}(1.36 \AA$ ) [34]. The value of the parameter $G$ is $0.0830(1)$ for $\mathrm{W}$ (near the value of Mo) [35]. According to the same source the $G$ parameter e.g. for the $\mathrm{Ca}$ ion is $0.084(2)$. The calculation procedure in the case of scheelite-type structures has been described in detail in a previous paper [5].

\section{Results and discussion}

Migration of $A$ ions in $A \mathrm{WO}_{4}$ was excluded since the radii of these ions are too large. For the $\mathrm{Ca}^{2+}$ or $\mathrm{Pb}^{2+}$ ions only voids that are not connected by channels were observed. Fig. 1 (a, b, c, and d) shows the 3D-network of migration channels of the $\mathrm{W}$ ions within the confines of one unit cell of the crystal structure of $\mathrm{PbWO}_{4}$. For some structural data continuous probable migration paths of $\mathrm{W}$ ions were calculated with the aid of the TOPOS program and visualized (Fig. 1d). In most cases, for the structural data used in the calculation, after selection of elementary channels with appropriate channel radii, continuous migration paths of the $\mathrm{W}$ ions were not observed (Fig. 1 a, b, and c). The cases (b) and (c) dominate.

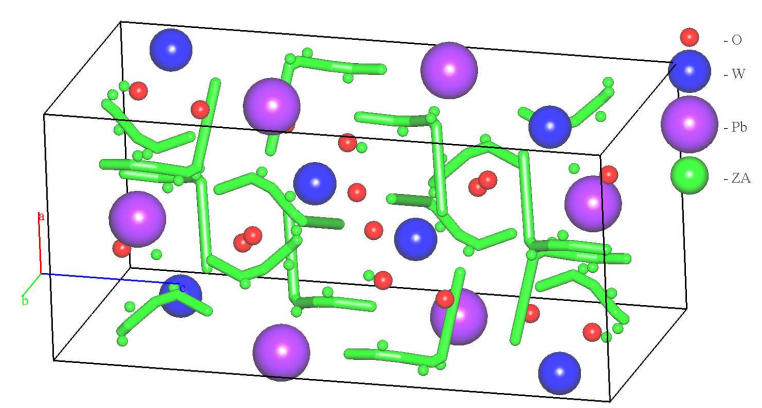

$\mathrm{b}$

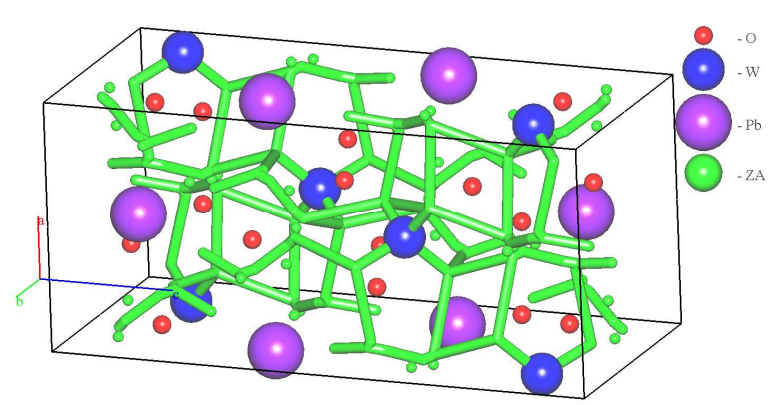

d

Fig. 1 Typical migration maps of $\mathrm{W}$ ions in the structure of $\mathrm{PbWO}_{4}$. X-ray data in (a) were taken from [18]; (b) own X-ray data; (c) [10]; (d) [16]. Drawings (a), (b), and (c) show paths with gaps, whereas (d) is a continuous path. 
The crystal structure of scheelite is based on two types of oxygen polyhedron with central $\mathrm{W}^{6+}$ or $A^{2+}$ ions surrounded by four and eight oxygen $\mathrm{O}^{2-}$ ions, respectively. Fig. 2 ( $a$ and b) shows the 3D-network of migration channels in the unit cell of the structure of $\mathrm{PbWO}_{4}$. The probable migration path of the $\mathrm{W}$ ions from position to position in the crystal structure (Fig. 2b) is completed via intermediate voids that are connected with the elementary channels. During the transfer, the W ion (position ZA10, connected with the nearby ZA9 elementary void) at the first step exits through the middle of an imaginary border of the oxygen tetrahedron. Then the $\mathrm{W}$ ion moves through the channel to the nearest void (second step) and up to a neighboring empty $\mathrm{W}$ position in the crystal structure. The migration path of the $\mathrm{W}$ ions considered here requires the existence of empty positions of $\mathrm{W}$ ions and of interstitial ions. Calculations at RT for the
W ions showed that they can pass through the channels if $r_{\mathrm{i}}>0.9(0.56+1.36)=1.728(\AA)$. Note that the shape of all the voids in the cases under consideration is approximately spherical $(G<0.1)$.

The technological conditions (Tables 1 and 2) of preparation of the $A \mathrm{WO}_{4}$ crystals play a principal role in the variation of the unit-cell volume and the lengths of the distances between voids (Fig. 3a,b) in the investigated compounds. For both cases of $A \mathrm{WO}_{4}$ crystals we observed a weak depencence of the distances between voids on the unit-cell volume. But large unit-cell volumes (see Tables 1 and 2, RT) favor the formation of continuous paths for probable $\mathrm{W}$-ion migration in the $A \mathrm{WO}_{4}$ crystals. With increasing unitcell parameters suitable void distances increase/decrease by linear or nonlinear laws (see curves on Fig. 3a,b).

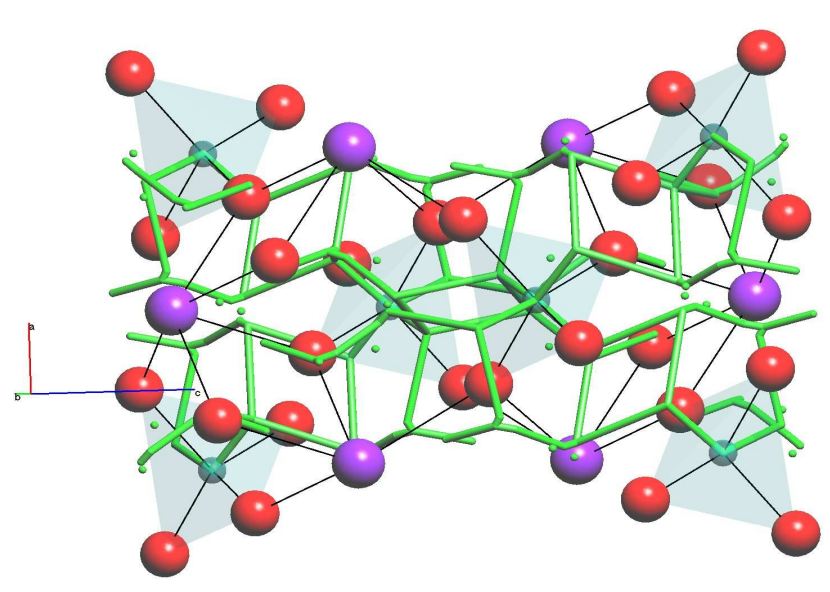

a
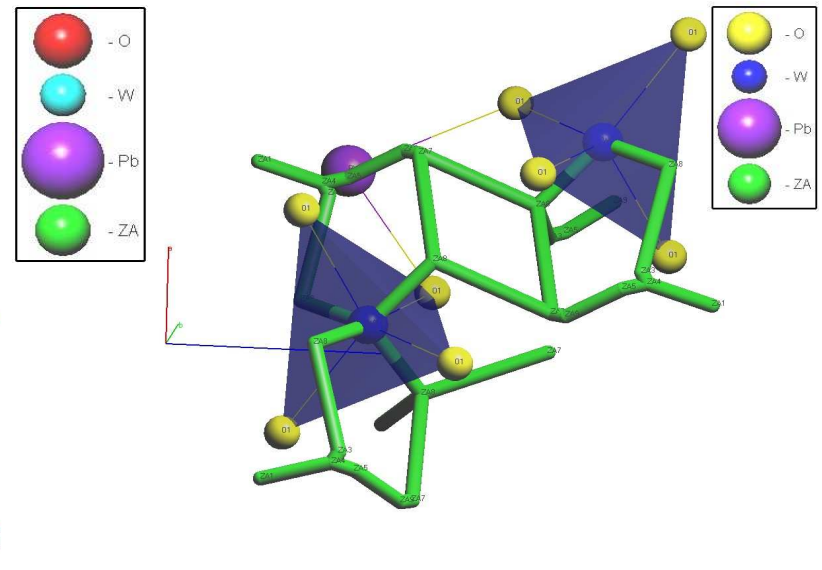

b

Fig. 2 Framework of $\mathrm{WO}_{4}{ }^{2-}$-complexes and three possible migration paths of the $\mathrm{W}$ ions in $\mathrm{PbWO}_{4}$ with scheelite-type structure (a) and a fragment of the migration path between two nearest W-ion positions (b). The calculation was performed for X-ray data from [16].

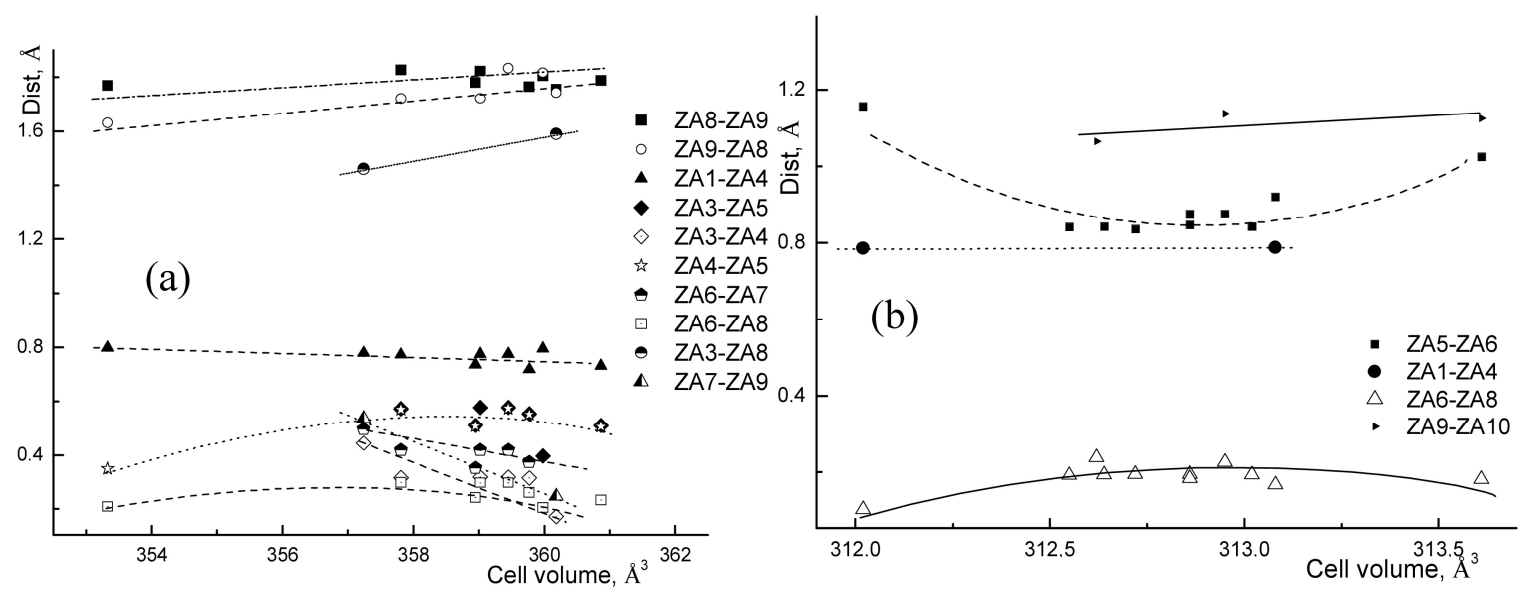

Fig. 3 Selected calculated distances between ZAN voids at RT as a function of the unit-cell volume for $\mathrm{PbWO}_{4}$ (a) and $\mathrm{CaWO}_{4}$ (b) prepared by different methods (see Table 1 and Table 2, respectively). 
The lengths of the distances between voids are modified not only by changing the unit-cell parameters but by varying the crystal temperature. Fig. 4 (a, b, c, and d) shows the temperature dependencies of the distances between ZAN-voids in possible migration channels of $\mathrm{W}$ ions. The calculations of the probable migration paths in the investigated crystals were performed for $\mathrm{PbWO}_{4}$ and $\mathrm{CaWO}_{4}$ using X-ray diffraction structure data from [19] and [23], respectively.

The curves on Fig. 4 (a, b, and c, $\mathrm{PbWO}_{4}$ crystal) show the situation at the particular temperatures of about 100 and $200 \mathrm{~K}$. At these temperatures, changes of the curves (change of the temperature dependence law) are observed. Up to $100 \mathrm{~K}$ increases of the channel lengths are not observed. In the temperature range $100-200 \mathrm{~K}$ there is linear increase/decrease of the channel lengths (links or the same as distances between neighboring voids). The features of the temperature dependence of the distances between voids in the $\mathrm{PbWO}_{4}$ crystals can be connected to the variation of other physical and structural properties [19] at 100 and $200 \mathrm{~K}$. The temperature dependence of the channel lengths indicates changes in the phonon contribution to the thermal properties of the investigated crystal at these temperatures.
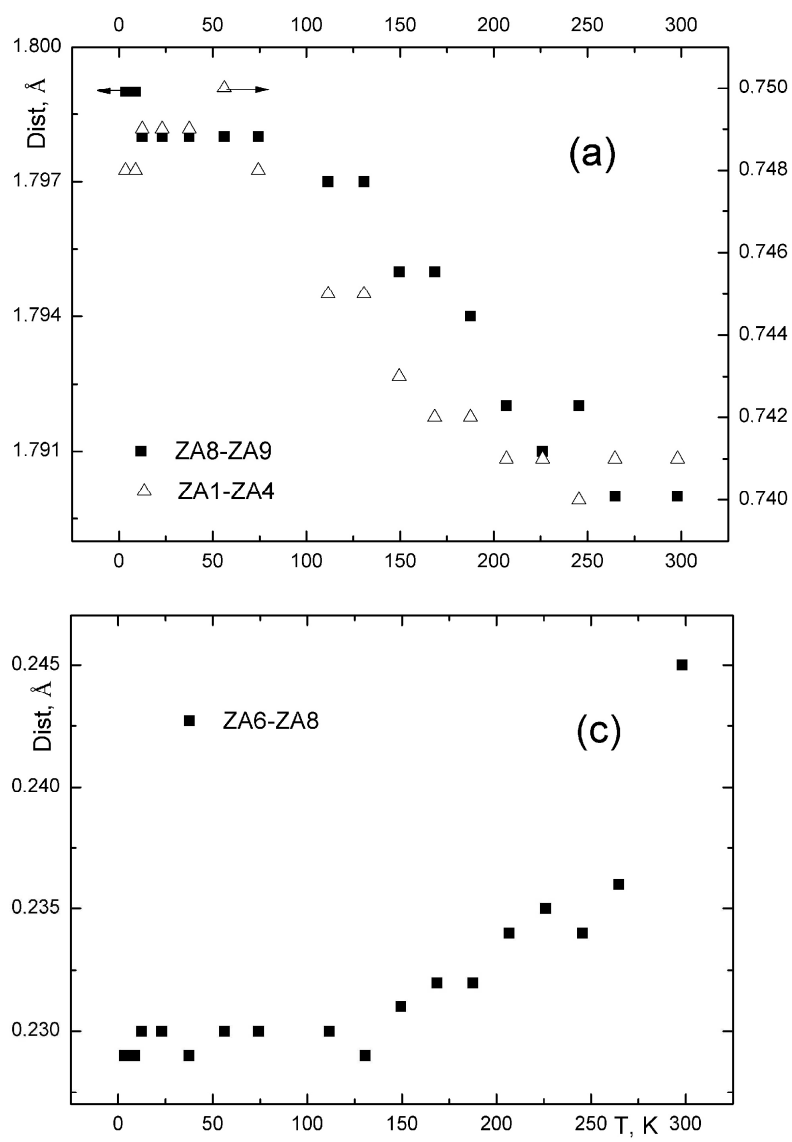

For $\mathrm{CaWO}_{4}$ at $T<200 \mathrm{~K}$ (Fig. 4d) the selected distances are independent of temperature variations. In the temperature range 200-1200 K linear dependencies were observed. At $T>1800 \mathrm{~K}$ in the some cases (see curves in Fig. 4d, bottom) nonlinear dependencies were seen.

Non-linear dependencies were also observed for the $\mathrm{Pb}-\mathrm{W}$ and $\mathrm{W}-\mathrm{W}$ distances in $\mathrm{PbWO}_{4}$ (Fig. 5, calculated for data from [19]) and, as can be seen from the results obtained in the temperature range $2-353 \mathrm{~K}$, also for some distances between $\mathrm{ZAN}$ voids in this compound (Fig. 4). In the temperature range $100-200 \mathrm{~K}$ both curves on Fig. 5 are satisfactorily approximated by a linear law. At $T<100 \mathrm{~K}$ and $T>200 \mathrm{~K}$ deviation from linearity is evident.

Introduction of $\mathrm{Eu}^{3+}$ ions replacing $\mathrm{Ca}^{2+}$ ions in the crystal structure of $\mathrm{CaWO}_{4}$ [21] caused variations of the elementary channel lengths and the shape of the migration path of the $\mathrm{W}$ ions (Fig. 6). In the case of the elementary channel ZA5-ZA6 a similar dependence on the $\mathrm{Eu}$ content was obtained for the band gap, with a minimum near $1 \mathrm{~mol} \% \mathrm{Eu}$. In the case of ZA6-ZA8 an analogous, but "reverse" dependence was observed.
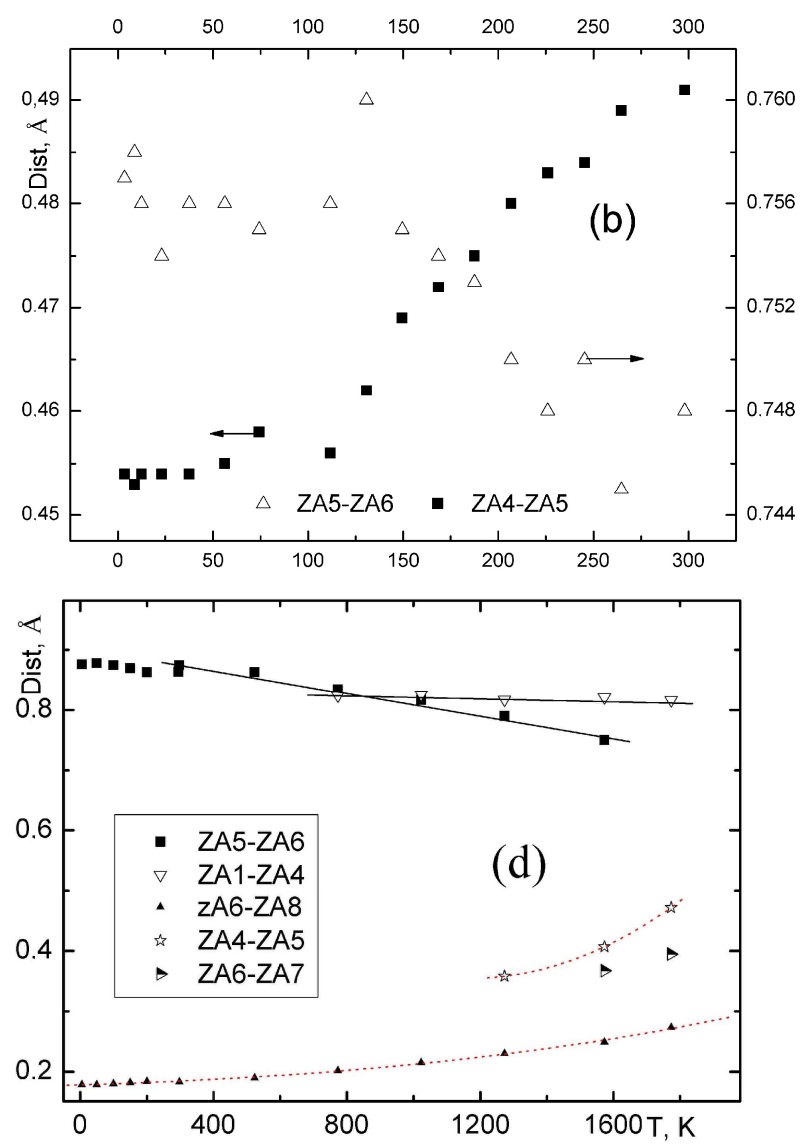

Fig. 4 Temperature dependencies of selected void distances for $\mathrm{PbWO}_{4}\left(\mathrm{a}, \mathrm{b}\right.$, and c) and $\mathrm{CaWO}_{4}(\mathrm{~d})$. The calculations were performed using X-ray data from [19] and [23], respectively. 


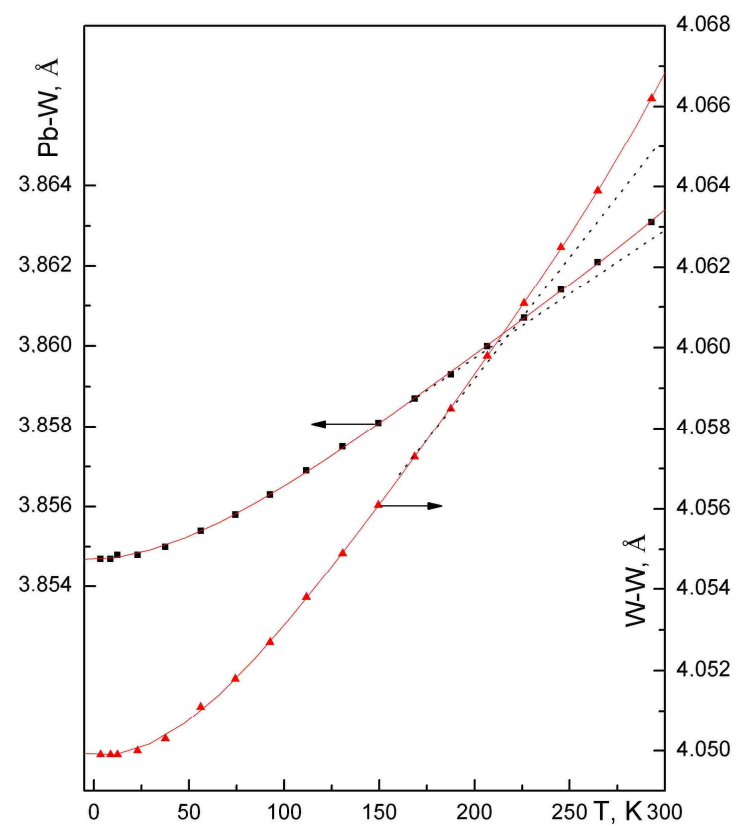

Fig. 5 Temperature dependencies of the $\mathrm{Pb}-\mathrm{W}$ and $\mathrm{W}-\mathrm{W}$ ion distances in $\mathrm{PbWO}_{4}$. The calculation was performed using X-ray data [19]. The dotted curves depict the linear law.

Data calculated for the ZAN voids and suitable connections are presented in Table 3 and Table 4 for $A=\mathrm{Ca}$ and $\mathrm{Pb}$, respectively. For the $A \mathrm{WO}_{4}$ compounds (e.g. X-ray data for [16] and [36]) a "quadrangle" (see Fig. 2) at the center of the unit cell is observed as a characteristic element of the migration channel, by which is monitored the migration of the mobile ions. The sides of this "quadrangle" are determined by the distances, as calculated in [5] for $\mathrm{PbWO}_{4}, \mathrm{ZA} 8-\mathrm{ZA7}$ (1.755 ̊) and ZA7-ZA8 (1.742 ^).

According to the approach used here, at RT the ionic conductivity in the structure of perfect $A \mathrm{WO}_{4}$ crystals is probably low. But in some cases possible continuous paths of $\mathrm{W}$-ion migration are formed already at RT. Higher temperatures (as shown in detail previously [4,5]) and structural defects, which are always present in real crystals, provide significant opportunities to form continuous migration paths for the mobile ions and, consequently, a possibility to increase the mobility of these ions. Ionic conductivity at high temperatures in $\mathrm{PbWO}_{4}$ and $\mathrm{PbMoO}_{4}$ crystals with scheelite-type structures was observed experimentally in [37]. The effect of migration of $\mathrm{WO}_{4}^{2-}$ tungstate polyatomic anions at high temperatures was investigated in [38], using molecular dynamics simulations as a supplementary tool for the study.

The investigations performed in this work showed that nano-particles of $A \mathrm{WO}_{4}$ with scheelitetype structures are promising materials for the possible existence of continuous paths of $\mathrm{W}$-ion migration. The parameters of the crystalline lattice (see Tables 1 and 2) and the lengths of the elementary channels are maximal in the case of nano-powders. The reduced particle size obviously favors the formation of continuous migration paths.

Table 3 Calculated positions of voids and channel lengths for $\mathrm{W}$-ion migration in $\mathrm{CaWO}_{4}$.

\begin{tabular}{|c|c|c|c|c|c|c|}
\hline \multirow{2}{*}{ Ref. } & \multirow{2}{*}{$\mathbf{Z A N}$} & \multicolumn{3}{|c|}{ Position } & \multirow{2}{*}{ Voids } & \multirow{2}{*}{ Channel length $(\AA)$} \\
\hline & & $x$ & $y$ & $z$ & & \\
\hline \multirow{4}{*}{$\begin{array}{c}{[23]} \\
5 \mathrm{~K}\end{array}$} & ZA5 & 0.64615 & 0.16354 & 0.65089 & ZA5-ZA6 & 0.876 \\
\hline & \multirow{2}{*}{ ZA6 } & \multirow{2}{*}{0.97278} & \multirow{2}{*}{0.70399} & \multirow{2}{*}{0.65459} & ZA6-ZA5 & 0.876 \\
\hline & & & & & ZA6-ZA8 & 0.179 \\
\hline & ZA8 & 0.03512 & 0.77220 & 0.66536 & ZA8-ZA6 & 0.179 \\
\hline \multirow{4}{*}{$\begin{array}{c}{[23]} \\
\mathrm{RT}\end{array}$} & ZA5 & 0.64641 & 0.16354 & 0.65034 & ZA5-ZA6 & 0.875 \\
\hline & \multirow{2}{*}{ ZA6 } & \multirow{2}{*}{0.97243} & \multirow{2}{*}{0.70332} & \multirow{2}{*}{0.65507} & ZA6-ZA5 & 0.875 \\
\hline & & & & & ZA6-ZA8 & 0.183 \\
\hline & ZA8 & 0.03569 & 0.77240 & 0.66604 & ZA8-ZA6 & 0.183 \\
\hline \multirow{4}{*}{$\begin{array}{l}\text { own } \\
\text { data }\end{array}$} & ZA5 & 0.64557 & 0.16596 & 0.64881 & ZA5-ZA6 & 0.846 \\
\hline & \multirow{2}{*}{ ZA6 } & \multirow{2}{*}{0.97181} & \multirow{2}{*}{0.70117} & \multirow{2}{*}{0.65494} & ZA6-ZA5 & 0.846 \\
\hline & & & & & ZA6-ZA8 & 0.195 \\
\hline & ZA8 & 0.03701 & 0.77302 & 0.66658 & ZA8-ZA6 & 0.195 \\
\hline \multirow{8}{*}{ [36] } & \multirow{3}{*}{ ZA4 } & \multirow{3}{*}{0.35633} & \multirow{3}{*}{0.66981} & \multirow{3}{*}{0.69297} & ZA4-ZA6 & 1.739 \\
\hline & & & & & ZA4-ZA6 & 1.521 \\
\hline & & & & & ZA4-ZA7 & 1.160 \\
\hline & ZA5 & 0.32902 & 0.36682 & 0.66002 & ZA5-ZA8 & 1.228 \\
\hline & \multirow{2}{*}{ ZA6 } & \multirow{2}{*}{0.04227} & \multirow{2}{*}{0.77359} & \multirow{2}{*}{0.68470} & ZA6-ZA4 & 1.521 \\
\hline & & & & & ZA6-ZA4 & 1.739 \\
\hline & ZA7 & 0.50000 & 0.75000 & 0.62500 & ZA7-ZA4 & 1.160 \\
\hline & ZA8 & 0.45252 & 0.28244 & 0.57716 & ZA8-ZA5 & 1.228 \\
\hline
\end{tabular}


V.N. Shevchuk, I.V. Kayun, Calculation of cation migration channels in crystals with scheelite-type structures

Table 4. Calculated positions of voids and channel lengths for $\mathrm{W}$-ion migration at $\mathrm{RT}$ in $\mathrm{PbWO}_{4}$ crystals.

\begin{tabular}{|c|c|c|c|c|c|c|}
\hline \multirow{2}{*}{ Ref } & \multirow{2}{*}{$\mathbf{Z A N}$} & \multicolumn{3}{|c|}{ Position } & \multirow{2}{*}{ Voids } & \multirow{2}{*}{ Channel length $(\AA)$} \\
\hline & & $x$ & $y$ & $z$ & & \\
\hline \multirow{14}{*}{ own data } & ZA1 & 0.87586 & 0.31459 & 0.76202 & ZA1-ZA4 & 0.774 \\
\hline & \multirow{2}{*}{ ZA3 } & \multirow{2}{*}{0.68489} & \multirow{2}{*}{0.11120} & \multirow{2}{*}{0.66520} & ZA3-ZA4 & 0.318 \\
\hline & & & & & ZA3-ZA5 & 0.577 \\
\hline & \multirow{2}{*}{ ZA4 } & \multirow{2}{*}{0.67351} & \multirow{2}{*}{0.15972} & \multirow{2}{*}{0.67883} & ZA4-ZA1 & 0.774 \\
\hline & & & & & ZA4-ZA3 & 0.318 \\
\hline & \multirow{2}{*}{ ZA5 } & \multirow{2}{*}{0.63829} & \multirow{2}{*}{0.17805} & \multirow{2}{*}{0.63473} & ZA5-ZA3 & 0.577 \\
\hline & & & & & ZA5-ZA4 & 0.574 \\
\hline & ZA6 & 0.96585 & 0.68436 & 0.65422 & ZA6-ZA7 & 0.419 \\
\hline & ZA7 & 0.00000 & 0.75000 & 0.66330 & ZA7-ZA6 & 0.420 \\
\hline & \multirow{3}{*}{ ZA8 } & \multirow{3}{*}{0.04775} & \multirow{3}{*}{0.77717} & \multirow{3}{*}{0.67051} & ZA8-ZA6 & 0.297 \\
\hline & & & & & ZA8-ZA9 & 1.721 \\
\hline & & & & & ZA8-ZA9 & 1.832 \\
\hline & \multirow{2}{*}{ ZA9 } & & & & ZA9-ZA8 & 1.832 \\
\hline & & 0.40656 & 0.91419 & 0.56001 & ZA9-ZA8 & 1.721 \\
\hline & ZA1 & 0.88833 & 0.31673 & 0.75716 & ZA1-ZA4 & 0.974 \\
\hline & 743 & 067871 & 011080 & 066100 & ZA3-ZA4 & 0.172 \\
\hline & LA3 & $0.0 / 8 / 1$ & 0.11980 & 0.00192 & ZA3-ZA8 & 1.590 \\
\hline & 7A4 & 067298 & 014663 & 066884 & ZA4-ZA1 & 0.974 \\
\hline & LA4 & $0.0 / 298$ & 0.14063 & 0.00884 & ZA4-ZA3 & 0.172 \\
\hline & $7 A 5$ & 065228 & 0.15900 & 064312 & ZA5-ZA4 & 0.337 \\
\hline & ZAJ & $0.05 \angle 28$ & 0.15900 & 0.04312 & ZA5-ZA9 & 0.912 \\
\hline & & & & & ZA7-ZA8 & 1.742 \\
\hline [11] & ZA7 & 0.04524 & 0.77524 & 0.67696 & ZA7-ZA8 & 1.755 \\
\hline & & & & & ZA7-ZA9 & 0.247 \\
\hline & & & & & ZA8-ZA3 & 1.590 \\
\hline & ZA8 & 0.34485 & 0.66345 & 0.69036 & ZA8-ZA7 & 1.742 \\
\hline & & & & & ZA8-ZA10 & 1.251 \\
\hline & $7 \Delta 0$ & & & 066302 & ZA9-ZA5 & 0.912 \\
\hline & LA9 & 0.96031 & 0.09363 & 0.06302 & ZA9-ZA7 & 0.247 \\
\hline & ZA10 & 0.50000 & 0.75000 & 0.62500 & ZA10-ZA8 & 1.251 \\
\hline & ZA1 & 0.89058 & 0.31376 & 0.76319 & ZA1-ZA4 & 0.880 \\
\hline & ZA3 & 0.66678 & 0.13115 & 0.66200 & ZA3-ZA9 & 1.600 \\
\hline & ZA4 & 0.66142 & 0.15593 & 0.66900 & ZA4-ZA1 & 0.880 \\
\hline & ZA5 & 0.64307 & 0.16663 & 0.64698 & ZA5-ZA6 & 0.879 \\
\hline & 7A6 & 097347 & 070447 & 065512 & ZA6-ZA5 & 0.879 \\
\hline & ZAO & 0.91347 & 0.10447 & 0.05512 & ZA6-ZA8 & 0.187 \\
\hline [19] & & & & & ZA8-ZA6 & 0.187 \\
\hline [19] & ZA8 & 0.03452 & 0.77155 & 0.66553 & ZA8-ZA9 & 1.852 \\
\hline & & & & & ZA8-ZA9 & 1.945 \\
\hline & & & & & ZA9-ZA10 & 1.202 \\
\hline & 7A9 & 040601 & 089911 & 056495 & ZA9-ZA3 & 1.600 \\
\hline & LAY & 0.40091 & 0.89911 & 0.50495 & ZA9-ZA8 & 1.852 \\
\hline & & & & & ZA9-ZA8 & 1.945 \\
\hline & ZA10 & 0.50000 & 0.75000 & 0.62500 & ZA10-ZA9 & 1.202 \\
\hline
\end{tabular}

\section{Conclusion}

Possible migration paths for the $\mathrm{W}$ ions in $\mathrm{CaWO}_{4}$ and $\mathrm{PbWO}_{4}$ crystals with scheelite-type structures were visualized using the program package TOPOS. The obtained calculated data correlate with experimental investigations of ionic electrical conductivity of scheelite-type crystals [37] and the observation of tungstate polyatomic anion migration [38] at high temperatures. The shape of the migration paths and the distances between voids are determined by the method and conditions of preparation, by the temperature, and the concentration of doping elements in the crystal structure (as shown for $\mathrm{Eu}$ in $\mathrm{CaWO}_{4}$ ). 

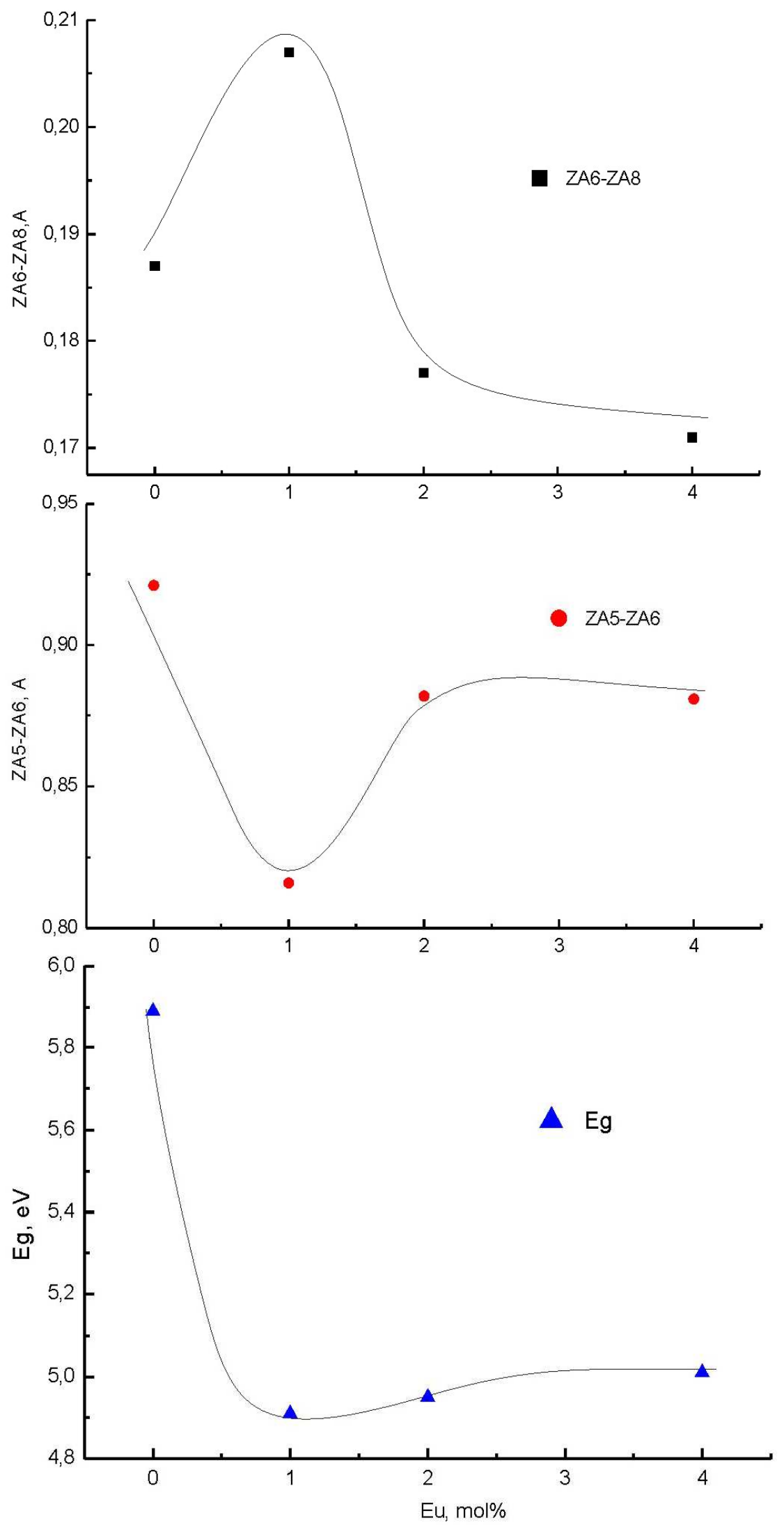

Fig. 6 Lengths of the ZA6-ZA8 and ZA5-ZA6 elementary channels (two top curves) and the band gap $E_{\mathrm{g}}$ (curve at the bottom) as a function of the content of $\mathrm{Eu}^{3+}$ (data from [21]). 
The analysis of the obtained results in most cases showed unlinked migration channels of the $\mathrm{W}$ ions in the $\mathrm{AWO}_{4}$ crystals, but for some structural data continuous 3D-networks of $\mathrm{W}$ migration may be considered even at RT. In some cases (e.g. for X-ray data of $\mathrm{PbWO}_{4}$ in [16] and $\mathrm{CaWO}_{4}$ in [36]) the probable continuous migration path of the $\mathrm{W}$ ions (mainly along [001]) passes through "intermediate" voids that are not equivalent to regular positions of the $\mathrm{W}$ ions in the crystal structure. The proposed migration path of the $\mathrm{W}$ ions, assuming spherical voids, requires the existence of vacant $\mathrm{W}$ positions and the presence of $\mathrm{W}$ ions at interstitial positions (ZAN voids) of the crystal structure.

\section{References}

[1] V.N. Shevchuk, I.V. Kayun, Acta Phys. Pol. A 117 (2010) 150-154.

[2] V.N. Shevchuk, I.V. Kayun, Chem. Met. Alloys 4 (2011) 72-76.

[3] V.N. Shevchuk, I.V. Kayun, Funct. Mater. 18 (2011) 165-170.

[4] V.N. Shevchuk, I.V. Kayun, Proc. Int. Conf. Oxide Materials for Electronic Engineering Fabrication, Properties and Applications OMEE-2014, 2014, Lviv, Ukraine, Publ. House Lviv Politeknika, Lviv, 2014, pp. 117-118.

[5] V.N. Shevchuk, I.V. Kayun, Chem. Met. Alloys 9 (2016) 128-134.

[6] V.N. Shevchuk, I.V. Kayun, Proc. X Int. Sci. Pract. Conf. Electronics and Information Technologies ELIT-2018, Lviv, Ukraine, Ivan Franko National University of Lviv, Lviv, 2018, pp. B82-B84.

[7] M.O. Filso, E. Eikeland, B.B. Iversen, AIP Conf. Proc. 1765 (2016) 020010 (5 p.).

[8] M.O. Filsoe, M.J. Turner, G.V. Gibbs, S. Adams, M.A. Spackman, B.B. Iversen, Chem. Eur. J. 19 (2013) 15535-15544.

[9] V.A. Blatov, IUCrCompCommNewsLetter 7 (2006) 4-38.

[10] J.M. Moreau, Ph. Galez, J.P. Peigneux, M.V. Korzhik, J. Alloys Compd. 238 (1996) 46-48.

[11] D. Errandonea, J. Pellicer-Porres, F.J. Manjón, A. Segura, Ch. Ferrer-Roca, R.S. Kumar, O. Tschauner, J. López-Solano, P. RodríguezHernández, S. Radescu, A. Mujica, A. Muñoz, G. Aquilanti, Phys. Rev. B 73 (2006) 224103 (15 p.).

[12] Sh. Takai, T. Nakanishi, K. Oikawa, S. Torii, A. Hoshikawa, T. Kamiyama, T. Esaka, Solid State Ionics 170 (2004) 297-304.

[13] Sh. Takai, Sh. Touda, K. Oikawa, K. Mori, Sh. Torii, T. Kamiyama, T. Esaka, Solid State Ionics 148 (2002) 123-133.

[14] R. Chipaux, G. André, A. Cousson, J. Alloys Compd. 325 (2001) 91-94.
[15] X. Kegin, X. Jiyue, D. Yang, Acta Geol. Sin. 8 (1995) 111-116.

[16] L.S. Cavalcante, J.C. Sczancoski, V.C. Albarici, J.M.E. Matos, J.A. Varela, E. Longo, Mater. Sci. Eng. B 150 (2008) 18-25.

[17] R. Saraf, C. Shivakumara, S. Behera, H. Nagabhushana, N. Dhananjaya, Spectrochim. Acta, Part A 136 (2015) 348-355.

[18] A. Grzechnik, W.A. Crichton, W.G. Marshall, K. Friese, J. Phys.: Condens. Matter 18 (2006) 3017-3029.

[19] D.M. Trots, A. Senyshyn, B.C. Shwarz, J. Solid State Chem. 183 (2010) 1245-1251.

[20] W. Hu, W. Tong, L. Li, J. Zheng, G. Li, Phys. Chem. Chem. Phys. 13 (2011) 11634-11643.

[21] R.F. Gonçalves, L.S. Cavalcante, I.C. Nogueira, E. Longo, M.J. Godinho, J.C. Sczancoski, V.R. Mastelaro, I.M. Pinatti, I.L.V. Rosa, A.P.A. Marques, CrystEngComm 17 (2015) 1654-1656.

[22] R.M. Hazen, L.W. Finger, J.W.E. Mariathasan, J. Phys. Chem. Solids 46 (1985) 253-263.

[23] A. Senyshyn, M. Hoelzel, T. Hansen, L. Vasylechko, V. Mikhailik, H. Kraus, H. Ehrenberg, J. Appl. Crystallogr. 44 (2011) 319-326.

[24] A. Taoufyq, F. Guinneton, J-C. Valmalette, M. Arab, A. Benlhachemi, B. Bakiz, S. Villain, A. Lyoussi, G. Nolibe, J-R. Gavarri, J. Solid. State Chem. 219 (2014) 127-137.

[25] S.P. Culver, M.J. Greaney, A. Tinoko, R.L. Brutchey, Dalton Trans. 44 (2015) 15042-15048.

[26] R. Vilaplana, R. Lacomba-Perales, O. Gomis, D. Erradonea, Y. Meng, Solid State Sci. 36 (2014) 16-23.

[27] R.D. Burbank, Acta Crystallogr. 18 (1965) 88-97.

[28] L.S. Cavalcante, V. M. Longo, J.C. Sczancoski, M.A.P. Almeida, A.A. Batista, J.A. Varela, M.O. Orlandi, E. Longo, M.S. Li, CrystEngComm 14 (2012) 853-868.

[29] V.N. Shevchuk, Yu.N. Usatenko, P.Yu. Demchenko, O.T. Antonyak, R.Ya. Serkiz, Chem. Met. Alloys 4 (2011) 67-71.

[30] P. Villars, K. Cenzual (Eds.), Pearson's Crystal Data - Crystal Structure Database for Inorganic Compounds, ASM International, Materials Park, Ohio, USA, Release 2015/16.

[31] V.A. Blatov, G.D. Ilyushin, O.A. Blatova, N.A. Anurova, A.K. Ivanov-Shits, L.N. Dem'yanets, Acta Crystallogr. B 62 (2006) 1010-1018.

[32] V. Shevchuk, I. Kayun, Proc. Fifth Int. Conf. Analytic Number Theory and Spatial Tessellation, Kyiv, Ukraine, National Pedagogical Dragomanov University, Kyiv, 2013, pp. 83-84.

[33] V. Shevchuk, I. Kayun, Electron. Inf. Technol. 3 (2013) 185-192 (in Ukrainian). 
V.N. Shevchuk, I.V. Kayun, Calculation of cation migration channels in crystals with scheelite-type structures

[34] B.K. Vainshtein (Ed.), Modern Crystallography, Vol. 2, Moscow, Nauka, 1979.

[35] V.A. Blatov, Crystallogr. Rev. $10 \quad$ (2004) 249-318.

[36] C. Shivakumara, R. Sarafh, S. Behera, N. Dhananjaya, N. Nagabhushana, Mater. Res. Bull. 61 (2015) 422-432.
[37] J.A. Groenink, H. Binsma, J. Solid State Chem. 29 (1979) 227-236.

[38] Y. Zhou, S. Adams, R.P. Rao, D.D. Edwards, A. Neiman, N. Pestereva, Chem. Mater. 20 (2008) 6335-6345. 